\title{
An Evolutionary Game Theoretical Analysis to Conflicts among Stakeholders Involved in the Operation of Municipal Waste Incineration
}

\author{
Yang Yu $\mathbb{D},{ }^{1}$ Rui Zhao $\mathbb{D}^{1},{ }^{1}$ Yuxin Huang $\mathbb{D},{ }^{1}$ and Linchuan Yang $\mathbb{D}^{2}$ \\ ${ }^{1}$ Faculty of Geosciences and Environmental Engineering, Southwest Jiaotong University, Chengdu 611756, China \\ ${ }^{2}$ Department of Urban and Rural Planning, Southwest Jiaotong University, Chengdu 611756, China \\ Correspondence should be addressed to Rui Zhao; ruizhaoswjtu@hotmail.com
}

Received 4 September 2020; Revised 24 October 2020; Accepted 27 November 2020; Published 12 December 2020

Academic Editor: Y. T. Peter Bian

Copyright ( $\odot 2020$ Yang Yu et al. This is an open access article distributed under the Creative Commons Attribution License, which permits unrestricted use, distribution, and reproduction in any medium, provided the original work is properly cited.

\begin{abstract}
This study presents an evolutionary game to model interactions among stakeholders with potential conflicts, including the operational enterprise of incineration plant, the local government, and the residents nearby. System dynamics is used to simulate the change of strategic actions corresponding to the three players, in order to seek for the evolutionary stability strategies. A numerical case is proposed to demonstrate the game theory application, in which the impacts of governmental incentive and punishment on the player's actions are investigated. The results indicated that administrative penalty is effective not only in motivating the enterprises to upgrade treatment facilities for ensuring environmental quality but also in helping the local government and residents to approach dominant strategies. Policy implications are given based on the results to lay out a foundation for the alleviation of the conflicts.
\end{abstract}

\section{Introduction}

Rapid urbanization has witnessed an increasing generation of municipal solid waste (MSW) in developing countries [1]. China, as a developing country with a large population, produces over 400 million tons of MSW annually, which gives rise to a remarkable issue as "besieged by waste" [2]. To mitigate such consequence, incineration is taken as an important alternative for waste treatment, beneficial not only for waste reduction, but also for energy recovery [3]. By the end of 2019, there are 418 incineration plants constructed in China [3, 4]. However, incineration face considerably strong protests from local communities, due to its negative externalities, for example, odor emissions and dioxins in its flue gas, resulting in a number of not-in-my-backyard (NIMBY) conflicts, including public petitions and street walks [5]. The NIMBY conflict indicates a contradicting phenomenon that the publics may object construction of built communal facility if it is close to their homes, though its potential benefits have been acknowledged [6].
A possible reason for the NIMBY conflicts is believed by the public risk perception, due to their limited knowledge and biased consciousness, who may amplify the associated impacts.For example, a decline in the quality of life and environment may give rise to a motive to oppose on the construction and operation of NIMBY facilities [7]. With regard to the incineration projects, more than ten anti-incinerator campaigns that claimed relocation of incineration facilities occurred in the recent decades [8].

Except for the public, local government is regarded as another sensitive stakeholder involved in the conflicts, since its intention on positively administrative practice may bring environmental and social benefits to communities that further reduces public risk perception [9]. The Chinese government has formulated a series of regulations on waste incineration projects, such as the revised "Regulations of the People's Republic of China on the Disclosure of Government Information" [10], the revised "Standard for pollution control on the municipal solid waste incineration" [11], and "Measures on Public Participation in Environmental Impact 
Assessment" [12]. These measures aim to improve the surveillance on the operation of incineration plant.For example, the pollutants emissions standards have been significantly improved, some of which are even stricter than the corresponding EU standards, to ensure public appeal on the maintenance of health safety and environmental quality [13]. Although the operational enterprises of incineration plant have to comply with those regulations, they are not willing to increase capital investment on technological upgrade to further improve the environmental quality regarding their workplaces. This is common in China's industries of waste treatment and disposal since they are deemed as the public welfare sectors, whose revenues mainly come from governmental subsidies [14].

Given the above interactions, it is implied that there are a number of interests and conflicts among the public, local government, and operational enterprise of incineration plant, to form a three players' game. For the enterprise, which is profitable motivated, it is unwilling to take more corporate social responsibility while having to act in accordance with the policy constraints [15]. The public, especially the residents nearby the incineration facility, may perceive the possible change of environmental quality to amplify their subjective risk [16]. In any case that they have not benefited from such an incineration project, e.g., job opportunity, traffic convenience, and environmental improvement, it may trigger their protests for compensations from the enterprise [17]. The government is devoted to improving environmental management to sanction the environmentally unfriendly behavior on the one hand and to full understanding of the public appeal on the other hand, ultimately creating a sustainable society [17, 18]. Game theory will allow a strategic model by taking the above actions to be examined, in order to provide an equilibrium strategy for mitigating possible conflicts among the three stakeholders.

As a classical game is generally limited by its assumption on complete rationality for the involved players [19], this study constructs an evolutionary game to investigate the transformation of the player's strategic actions, thus identifying the appropriate strategic action for alleviating the conflicts regarding the operation of waste incineration. System dynamics (SD) is used to test such actions and predict their future development. The joint application of evolutionary game theory and system dynamics may maximize their advantages, which facilitates the investigation of the dynamic change of equilibrium strategy [20]. The potential findings are expected to better understand the interactions of multi-stakeholders involved in the conflicts regarding waste incineration and provide insightful perspectives on policy implications in the mitigation of such conflicts. A game's solution is generally indicated by Nash equilibrium, which is the unique and ultimate prediction of the strategic actions that each player may choose [21]. However, the dynamic process for seeking such an equilibrium strategy cannot be visualized, by which the decisionmaker may not fully understand how the game evolves [20]. System dynamics fills the gap to investigate the game equilibrium by changing the embodied variables to highlight their transient transformation features [22, 23]. The contributions of this study are specified as proposing an evolutionary game to model the players' possible behaviors, combining the SD approach with the proposed game to investigate the behavioral change and shedding light on mitigation of the conflicts.

The rest of the paper is structured as follows: Section 2 reviews the game theory application to NIMBY conflicts and highlights the contribution of the study; Section 3 proposes an evolutionary game to explore the possible strategic actions for the involved players; Section 4 gives a case example to demonstrate the application of game model by using system dynamics simulation; and Section 5 presents the conclusion and policy implications.

\section{Literature Review}

The game theory developed by John von Neumann and Oskar Morgenstern [24] has been widely applied to study environmental conflicts, such as prediction of strategic action by the involved stakeholders to assist in site selection for environmental governance project, identification of the key factors to influence the strategic decision-making, and so forth.

Abdollahian et al. [25] took the high voltage transmission project as an example to develop a siting policy based on the stakeholders' responses by using noncooperation game theory. Karmperis et al. [26] also took interactions of the stakeholders into account to establish a game theory-driven decision support framework to manage stockpiled solid waste. A further study was implemented by Soltani et al. [27], who combined game theory with cost-benefit theory to solve the conflicts in stockpiling site for municipal solid waste. Cho and Park [28] applied game theory and transaction cost theory to solve the conflicts involved in the selection of Korea waste treatment and disposal plant sites. Mei et al. [29] focused on game theory application to the site selection for the power grid and decision-making on the power system control. Da-Silva-Rocha and Salomão [30] constructed a two-person mixed game to predict the strategic actions between the auditor and enterprise that discharges pollutants, by which the cost of inspection was identified as the key influencing factor to affect the game outcome. Under the action of punishment mechanism, Xu et al. [31] analysed the strategic responses of the environmental services organization and pollutant discharging enterprise, respectively. They found that dynamic punishment may aggravate the illegal motives of the two stakeholders. Xu et al. [3] further gave considerations to risk and profit sharing for the regional authority to trade off the conflicts between environmental quality and economic revenue in a waste incineration project. Oftadeh et al. [32] applied a two-player ultimatum game to mitigate the regional water conflicts between environmental reclamation and economic satisfaction, indicating ecological compensation is useful to coordinate the above two criteria and conduct efficient watershed water allocation. Such implication was further validated by Aghasian et al. [33], who proposed a bankruptcy form of the game theory model to 
enhance watershed water quality management through ecological compensation incentivizing emissions trading. Sheng et al. [34] constructed a three players' evolutionary game to model the conflicts involved in environmental regulations, by which the governmental supervision was identified as the effective mean to strengthen the regulations. Halkos and Papageorgiou [35] based on the Stackelberg differential game explored the interactions among public debts, pollutant emissions, and taxation. To improve the atmospheric quality of coastal areas, Jiang et al. [36] constructed an evolutionary game to discuss the conflicts of economic benefits obtained by government and shipping companies in implementation of China's Emissions Control Policy.

The above studies admitted that game theory is useful to describe possible conflicts among stakeholders by using a representative mathematical model to highlight the corresponding strategic actions in a payoff form. However, the existing studies are mainly limited to the static game with two players, while few studies consider the trade-offs among government, enterprises of NIMBY facilities, and the public. In addition, few studies have discussed the conflicts among waste incineration project. This study proposed an evolutionary game model to investigate strategic actions of multiple stakeholders in an incineration scenario, thus providing implications to mitigate the possible conflicts and promote its sustainable operation.

\section{Evolutionary Game Model}

3.1. Game Model Construction. The static Nash equilibrium defined by von Neumann and Morgenstern cannot explain the dynamic interactions of stakeholders in conflicts, which facilitates the development of the evolutionary game [37]. With the adoption of the natural selection mechanism rather than the strict rational assumption, the evolutionary game can reflect the evolution process of strategies for different stakeholders reasonably, making it an important and powerful tool to study the dynamic characteristics of multigroup game behavior [38].

The strategic actions taken by each player are not only affected by their own decisions but also influenced by other players. For the enterprise, it has two strategic options: one is to upgrade and optimize its treatment facilities to enhance the environmental quality (UT), including odor reduction and purification of flue gas, and the other one is to keep no change to the existing facilities (NUT). The local government has two strategic options, indicating that one is a regular inspection on the operation of the incineration plant (RI), while the other one is to implement irregular inspection (IRI). With regard to the residents nearby, their strategic options are discriminated by whether they appeal or not to compensation for their quality of life and environment (AC, NAC).
According to the above strategic actions, the game proposes the following assumptions:

(1) All the involved players are hypothesized as rational economic men with bounded rationality, and their decision-making is set based upon maximization of their own interests.

(2) The probability that the enterprise does not upgrade treatment facilities is given as $p_{1}$, whilst the probability of upgrading is $1-p_{1}$. The probability that the local government imposes regular inspection on the incineration plant is $p_{2}$, and the probability of irregular inspection is $1-p_{2}$. The probability that the residents call for compensation is $p_{3}$, and the probability of not calling for compensation is $1-p_{3}$.

The specifically designed parameters to compose the game and their interpretations are given in Table 1.

The payoffs of the three players with their different strategic options are shown in Table 2.

3.2. The Replicated Dynamic Equation. According to the payoff matrix among the three players, $P_{1}, P_{2}$, and $P_{3}$ are used to denote the expected payoff functions of the enterprise, government, and residents, respectively:

$$
\begin{aligned}
P_{1}= & p_{1}\left(B_{a}+B_{b}-A_{e}-T-p_{2} D_{g}-p_{3} D_{p}\right) \\
& +\left(1-p_{1}\right)\left(B_{a}+B_{b}-A_{e}-A_{\mathrm{eu}}-T\right), \\
P_{2}= & p_{2}\left(p_{1} D_{g}-p_{3} A_{g_{1}}+T-B_{b}-A_{g_{2}}\right) \\
& +\left(1-p_{2}\right)\left(T-B_{b}-p_{3} A_{g_{1}}\right), \\
P_{3}= & p_{3}\left(p_{1} D_{p}-A_{p}-p_{1} E\right)+\left(1-p_{3}\right)\left(-p_{1} E\right) .
\end{aligned}
$$

Thus, the replication dynamic equations $F\left(p_{i}\right)$ corresponding to the enterprise $F\left(p_{1}\right)$, government $F\left(p_{2}\right)$, and residents $F\left(p_{3}\right)$ are expressed as follows:

$$
\begin{aligned}
& F\left(p_{1}\right)=\frac{\mathrm{d} p_{1}}{\mathrm{~d} t}=p_{1}\left(1-p_{1}\right)\left(A_{\mathrm{eu}}-p_{2} D_{g}-p_{3} D_{p}\right), \\
& F\left(p_{2}\right)=\frac{\mathrm{d} p_{2}}{\mathrm{~d} t}=p_{2}\left(1-p_{2}\right)\left(p_{1} D_{g}-A_{g_{2}}\right), \\
& F\left(p_{3}\right)=\frac{\mathrm{d} p_{3}}{\mathrm{~d} t}=p_{3}\left(1-p_{3}\right)\left(p_{1} D_{p}-A_{p}\right) .
\end{aligned}
$$

3.3. Game Theoretical Analysis. The replication dynamic equation reflects the evolution speed and direction regarding the involved players [39]. When $F\left(P_{i}\right)=0$, the game reaches a relatively stable equilibrium state. Letting $F(x)=\left(F\left(p_{1}\right), F\left(p_{2}\right), F\left(p_{3}\right)\right) T=0$, the Nash Equilibrium of the evolutionary game can be obtained as follows: 


$$
\begin{aligned}
& x_{1}=\left\{\begin{array}{l}
0 \\
0, \\
0
\end{array}\right. \\
& x_{2}=\left\{\begin{array}{l}
0 \\
0, \\
1
\end{array}\right. \\
& x_{3}=\left\{\begin{array}{l}
0 \\
1, \\
0 \\
x_{4}
\end{array}\right. \\
& x_{5}=\left\{\begin{array}{l}
0 \\
1, \\
1 \\
0, \\
0
\end{array}\right. \\
& x_{6}=\left\{\begin{array}{l}
1 \\
0, \\
1 \\
x_{9}
\end{array}\right. \\
& x_{7}=\left\{\begin{array}{l}
1, \\
1, \\
0 \\
1, \\
1
\end{array}\right.
\end{aligned}
$$

Specifically, $x_{9}$ is the solution of

$$
\left\{\begin{array}{l}
A_{\mathrm{eu}}-p_{2} D_{g}-p_{3} D_{p}=0, \\
p_{1} D_{g}-A_{g_{2}}=0, \\
p_{1} D_{p}-A_{p}=0 .
\end{array}\right.
$$

The stability of the above equilibrium points can be judged by the Jacobian matrix via local stability analysis [40]. When the equilibrium points satisfy the matrix determinant $\operatorname{det}(J)>0$ and the matrix $\operatorname{trace} \operatorname{tr}(J)<0$, they are defined as the asymptotically stable fixed points, entitled the evolutionary stability strategy $[20,40]$ : 


$$
\begin{aligned}
& F_{11}=\frac{\partial F\left(p_{1}\right)}{\partial p_{1}}=\left(1-2 p_{1}\right)\left(A_{\mathrm{eu}}-p_{2} D_{g}-p_{3} D_{p}\right), \\
& F_{12}=\frac{\partial F\left(p_{1}\right)}{\partial p_{2}}=-D_{g} p_{1}\left(1-p_{1}\right), \\
& F_{13}=\frac{\partial F\left(p_{1}\right)}{\partial p_{3}}=-D_{p} p_{1}\left(1-p_{1}\right), \\
& F_{21}=\frac{\partial F\left(p_{2}\right)}{\partial p_{1}}=D_{g} p_{2}\left(1-p_{2}\right), \\
& F_{22}=\frac{\partial F\left(p_{2}\right)}{\partial p_{2}}=\left(1-2 p_{2}\right)\left(p_{1} D_{g}-\mathrm{A}_{\mathrm{g}_{2}}\right), \\
& F_{23}=\frac{\partial F\left(p_{2}\right)}{\partial p_{3}}=0, \\
& F_{31}=\frac{\partial F\left(p_{3}\right)}{\partial p_{1}}=p_{3}\left(1-p_{3}\right) D_{p}, \\
& F_{32}=\frac{\partial F\left(p_{3}\right)}{\partial p_{2}}=0, \\
& F_{33}=\frac{\partial F\left(p_{3}\right)}{\partial p_{3}}=\left(1-2 p_{3}\right)\left(p_{1} D_{p}-A_{p}\right), \\
& J=\left[\begin{array}{lll}
F_{11} & F_{12} & F_{13} \\
F_{21} & F_{22} & F_{23} \\
F_{31} & F_{32} & F_{33}
\end{array}\right] \\
& =\left[\begin{array}{ccc}
\left(1-2 p_{1}\right)\left(A_{\mathrm{eu}}-p_{2} D_{g}-p_{3} D_{p}\right) & -D_{g} p_{1}\left(1-p_{1}\right) & -D_{p} p_{1}\left(1-p_{1}\right) \\
D_{g} p_{2}\left(1-p_{2}\right) & \left(1-2 p_{2}\right)\left(p_{1} D_{g}-A_{g_{2}}\right) & 0 \\
p_{3}\left(1-p_{3}\right) D_{p} & 0 & \left(1-2 p_{3}\right)\left(p_{1} D_{p}-A_{p}\right)
\end{array}\right] \text {. }
\end{aligned}
$$

According to Lyapunov's method, the equilibrium point is an ESS, only if all the eigenvalues in the Jacobian matrix have negative real parts $[40,41]$. If all the eigenvalues in the Jacobian matrix are positive, the equilibrium point is deemed as an unstable point [40,41]. If there is one or two positive numbers in the eigenvalues of the Jacobian matrix, the equilibrium point is taken as a saddle point [40-42]. In this study, we only test the equilibrium points $x_{1}$ to $x_{8}$, as the solution of a three player's evolutionary game is typically a strict Nash equilibrium [43]. The eigenvalues for the equilibrium points $x_{1}$ to $x_{8}$ are given in Table 3 .

Since $A_{\mathrm{eu}}>0, A_{p}>0$, and $A_{g_{2}}>0$, the equilibrium points $(0,0,0),(0,0,1),(0,1,0)$, and $(0,1,1)$ may be unstable points or saddle points. The equilibrium points $(1,0,0),(1,0,1)$, $(1,1,0)$, and $(1,1,1)$ may be the potential evolutionary stability strategies. Among these potential ESS, the strategy that residents appeal not to compensation (NAC) is the ideal stability strategy.
The equilibrium point $(1,0,0)$ is the ESS, when $D_{q}-$ $A_{g_{2}}<0$ and $D_{p}-A_{p}<0$. The equilibrium point $(1,0,0)$ is a saddle point, when $-A_{\mathrm{eu}}, D_{g}-A_{g_{2}}$, and $D_{p}-A_{p}$ have one or two positive numbers. Under the conditions that enterprise keeps no change to the existing facilities (NUT) and residents appeal not to compensation (NAC), the local government may adopt irregular inspection on the operation of incineration plant (IRI). The equilibrium point $(1,1,0)$ is discussed similarly. When $D_{g}-A_{\mathrm{eu}}<0, A_{g_{2}}-D_{g}<0$, and $D_{p}-A_{p}<0$, the equilibrium point $(1,1,0)$ is the ESS. When $D_{g}-A_{\mathrm{eu}}>0, A_{g_{2}}-D_{g}>0$, and $D_{p}-A_{p}>0$, the equilibrium point $(1,1,0)$ is an unstable point. When $D_{g}-A_{\text {eu }}$, $A_{g_{2}}-D_{q}$, and $D_{p}-A_{p}$ have one or two positive numbers, the equilibrium point $(1,1,0)$ is a saddle point. The results indicate that the enterprise adopts strategic action as NUT, if its upgrading cost of treatment facilities is greater than the administrative penalty. The government imposes "regular 
TABle 1: Model parameters.

\begin{tabular}{lc}
\hline Parameter & Interpretation \\
\hline$B_{a}$ & Enterprise's income from power generation \\
$B_{b}$ & Enterprise' income from waste disposal \\
$A_{e}$ & Operation and maintenance cost of incineration plant \\
$A_{\mathrm{eu}}$ & Cost of treatment facilities upgrade \\
$A_{g_{1}}$ & Social cost \\
$A_{g_{2}}$ & Inspection cost \\
$A_{p}$ & Cost of residents appealing to compensation \\
$T$ & Tax revenue \\
$D_{p}$ & Compensation for residents \\
$D_{g}$ & Administrative penalty by the enterprise \\
$E$ & Health loss associated with typical diseases of \\
\hline
\end{tabular}

inspection" (RI) action if its inspection cost is less than the administrative penalties by the enterprise. The residents choose not calling for compensation (NAC) if the received compensation is less than their cost.

3.4. System Dynamics Model. To reflect the dynamic evolution of the strategic actions, the study adopts SD to investigate the game evolution process, thus to seek for the possible stability strategies. The study uses the Vensim software package to build the SD model. The SD model in this study is composed of three subsystems, namely, the enterprise's subsystem, the government's subsystem, and the residents' subsystem, respectively. The model consists of 3 level variables, 3 flow variables, 10 external variables, and 21 intermediate variables, given in Table 4 . The level variables represent the probability of strategic actions that the involved stakeholders may choose, including the actions related to the enterprise, government, and residents, respectively. The flow variables represent the rate of change corresponding to the probability of the strategic actions. The external variables have been claimed in the hypotheses of the proposed game model. Intermediate variables are the possible influencing factors related to the stakeholders' payoffs, which come from similar studies and field investigations. For example, Song et al. [44] pointed out that polluting enterprises should be responsible for providing necessary environmental compensations to the nearby affected residents to reduce possible health damage. At the same time, the residents may perceive potential environmental impact resulting from the enterprise's operation and bargain for compensation for their life quality [45]. Besides, governmental supervision and incentives can be the drivers to compel enterprises to improve environmental quality, thus responding to the public's concern with environmental health $[34,35]$.

For the enterprise, its expected payoffs mainly reflect in whether upgrading facilities or not, which are determined by the profit from power generation, cost of waste incineration, cost of upgrading facilities, and administrative penalties, shown in Figure 1(a). The improvement of environmental quality by upgrading treatment facilities may bring marginal cost [46]. In such a case, it may be unwilling to take such action unless the possible benefits cover the cost; that is, the expected payoff is above 0 . Based on the above analysis, there are two key causal loops in the enterprise's subsystem:

Reinforcing loop: probability that the enterprise upgrades facilities $\longrightarrow$ health loss that residents exposed to environment $\longrightarrow$ administrative penalties $\longrightarrow$ enterprise's expected payoffs with upgrading facilities $\longrightarrow$ probability that the enterprise upgrades facilities

Balancing loop: probability that the enterprise upgrades facilities $\longrightarrow$ health loss that residents exposed to environment $\longrightarrow$ expected payoffs of governmental regular inspection $\longrightarrow$ probability that government implements regular inspection $\longrightarrow$ probability that the enterprise upgrades facilities

The payoffs of government's subsystem are decided by the cost of governmental regular inspection, administrative penalties from the enterprise, and emergency cost for mass unexpected incidents, shown in Figure 1(b). The primary responsibility of the local government is to drive enterprises' compliance with environmental regulations through either economic policy tools, including tax preference and subsidy, or administrative sanction $[15,34,35]$. At the same time, the local government takes the responsibility of understanding the public's appeal to improve environmental quality, thus avoiding possible group conflicts $[47,48]$. There are two key causal loops in the government's subsystem, defined as follows:

Reinforcing loop: expected payoffs of governmental regular inspection $\longrightarrow$ probability that government implements regular inspection $\longrightarrow$ probability that the enterprise upgrades facilities $\longrightarrow$ health loss that residents exposed to environment $\longrightarrow$ administrative penalties $\longrightarrow$ expected payoffs of the governmental regular inspection

Balancing loop: probability that the government implements regular inspection $\longrightarrow$ probability that the enterprise upgrades facilities $\longrightarrow$ health loss that residents exposed to environment $\longrightarrow$ expected payoffs of governmental regular inspection $\longrightarrow$ probability that government implements regular inspection

The nearby residents may bargain with the enterprise for possible compensation regarding their perceived health damage [42]. Their expected payoffs are determined by compensation from the enterprise, possible health loss, and the cost of complaints, shown in Figure 1(c). The two key causal loops in the residents' subsystem are defined as follows:

Reinforcing loop: probability that residents appeal to compensation $\longrightarrow$ probability that government implements regular inspection $\longrightarrow$ probability that enterprise upgrades facilities $\longrightarrow$ health loss that residents exposed to environment $\longrightarrow$ expected payoffs of residents who appeal to compensation $\longrightarrow$ probability that residents appeal to compensation 
TABLE 2: Payoffs matrix for the three players.

\begin{tabular}{|c|c|c|c|}
\hline \multirow{2}{*}{ Enterprise } & \multirow{2}{*}{ Government } & \multicolumn{2}{|l|}{ Residents } \\
\hline & & $\mathrm{AC}\left(p_{3}\right)$ & NAC $\left(1-p_{3}\right)$ \\
\hline $\operatorname{NUT}\left(p_{1}\right)$ & $\begin{array}{c}\mathrm{RI}\left(p_{2}\right) \\
\mathrm{IRI}\left(1-p_{2}\right)\end{array}$ & $\begin{array}{c}\left(B_{a}+B_{b}-A_{e}-T-D_{g}-D_{p}, T+D_{g}-A_{g_{1}}-A_{g_{2}}-B_{b}\right. \\
\left.D_{p}-E-A_{p}\right) \\
\left(B_{a}+B_{b}-A_{e}-T-D_{p}, T-A_{g_{1}}-B_{b}, D_{p}-E-A_{p}\right)\end{array}$ & $\begin{array}{c}\left(B_{a}+B_{b}-A_{e}-T-D_{g}, T+D_{g}-A_{g_{2}}-B_{b},\right. \\
-E) \\
\left(B_{a}+B_{b}-A_{e}-T, T-B_{b},-E\right) \\
\end{array}$ \\
\hline $\mathrm{UT}\left(1-p_{1}\right)$ & $\begin{array}{c}\text { RI }\left(p_{2}\right) \\
\text { IRI }\left(1-p_{2}\right)\end{array}$ & $\begin{array}{c}\left(B_{a}+B_{b}-A_{e}-A_{\mathrm{eu}}-T, T-B_{b}-A_{g_{2}}-A_{g_{1}},-A_{p}\right) \\
\left(B_{a}+B_{b}-A_{e}-A_{\mathrm{eu}}-T, T-B_{b}-A_{g_{1}},-A_{p}\right)\end{array}$ & $\begin{array}{c}\left(B_{a}+B_{b}-A_{e}-A_{\mathrm{eu}}-T, T-B_{b}-A_{g_{2}}, 0\right) \\
\left(B_{a}+B_{b}-A_{e}-A_{\mathrm{eu}}-T, T-B_{b}, 0\right)\end{array}$ \\
\hline
\end{tabular}

Balancing loop: probability that residents appeal to compensation $\longrightarrow$ probability that the enterprise upgrades facilities $\longrightarrow$ health loss that residents exposed to environment $\longrightarrow$ expected payoffs of residents who appeal to compensation $\longrightarrow$ probability that residents appeal to compensation

\section{A Numerical Example}

In this section, a numerical example is provided to verify the application of the proposed three players' game. A municipal incineration plant located in Nanchong City, Southwestern China, which has been paid great public attention is selected as a case study. The plant was completed in 2018 with a maximum processing capacity of 800 ton per day. According to a field survey, only 40 households live within a 1-kilometre radius around the plant and the rest have been relocated. $93 \%$ of the respondents pointed out that they feel depressed towards the operation of the incineration plant, for example, worrying about their health and crops as a result of the odor and smoke. The input parameters for the SD model are mainly obtained by field investigation and similar studies, as shown in Table 5 .

\section{Results and Discussion}

5.1. Simulation Results. According to Section 3.3 as the analysis of evolutionary stability strategy, when $D_{g}-A_{\text {eu }}<0, A_{g_{2}}-D_{g}<0$, and $D_{p}-A_{p}<0$, the game finally achieves evolutionary stability, and the equilibrium point $(1,1,0)$ corresponds to the pair of strategic actions as [NUT, RI, NAC]. In such a case, the initial probability that the enterprise prefers not upgrading treatment facilities is set as $p_{1}=0.7$, the initial strategy that the government imposes regular inspection as $p_{2}=0.5$, and the initial strategy that the residents appeal to environmental compensation as $p_{3}=0.5$, respectively. Figure 2 shows that the three players can follow stable strategic actions after a short term of simulation (about 5 to 15 years), indicating that the proposed game has stable equilibrium points.

It is clear that the probability of NUT $1-p_{1}$, the probability of RI $p_{2}$, and the probability of $\mathrm{AC} p_{3}$ all converge to a stable strategic equilibrium point sets as $(0.66$, $1,0)$, respectively. Such phenomenon implies dominant strategies for both local government and residents; that is, the local government will impose regular surveillance on the enterprise's operational behavior, whilst the residents choose not to appeal to compensation.
TABle 3: The main eigenvalues for the equilibrium points.

\begin{tabular}{lccc}
\hline$\left(p_{1}, p_{2}, p_{3}\right)$ & $F_{11}$ & $F_{22}$ & $F_{33}$ \\
\hline$(0,0,0)$ & $A_{\mathrm{eu}}$ & $-A_{g_{2}}$ & $-A_{p}$ \\
$(0,0,1)$ & $A_{\mathrm{eu}}-D_{p}$ & $-A_{g_{2}}$ & $A_{p}$ \\
$(0,1,0)$ & $A_{\mathrm{eu}}-D_{g}$ & $A_{g_{2}}$ & $-A_{p}$ \\
$(0,1,1)$ & $A_{\mathrm{eu}}-D_{g}-D_{p}$ & $A_{g_{2}}$ & $A_{p}$ \\
$(1,0,0)$ & $-A_{\mathrm{eu}}$ & $D_{g}-A_{g_{2}}$ & $D_{p}-A_{p}$ \\
$(1,0,1)$ & $-A_{\mathrm{eu}}+D_{p}$ & $D_{g}-A_{g_{2}}$ & $-D_{p}+A_{p}$ \\
$(1,1,0)$ & $-A_{\mathrm{eu}}+D_{g}$ & $-D_{g}+A_{g_{2}}$ & $D_{p}-A_{p}$ \\
$(1,1,1)$ & $-A_{\mathrm{eu}}+D_{g}+D_{p}$ & $-D_{g}+A_{g_{2}}$ & $-D_{p}+A_{p}$ \\
\hline
\end{tabular}

Note: $F_{12}=F_{13}=F_{21}=F_{23}=F_{31}=F_{32}=0$.

For the enterprise, it has the potential of upgrading its treatment facilities to solve the issues related to odor emissions, as its strategic probability is slightly above 0.5 (shown in Figure 2(a)). Among the three players, the probability of governmental action converges the slowest (shown in Figure 2(b)), while the residents' strategic action converges the fastest (shown in Figure 2(c)).

5.2. Influence of Incentive and Punishment on Strategic Actions. The above simulation results indicate that the enterprise has a probability of 0.66 to upgrade its treatment facilities, which lays room for further improvement. In such a case, this study constructs an incentive scenario and a sanction scenario to compare their performances on the strategic actions of the three players.

As cost and benefit is the key influencing factor to drive the enterprise whether implementing technological innovation or not, the incentive scenario mainly focuses on giving governmental subsidies to cover the upgrade cost regarding facilities of deodorization. Figure 3 shows the variation of strategic actions corresponding to the three players. It can be seen that the strategy equilibrium points have not varied for the three players, but their rates of convergence are apparently different. The probability of enterprise's action converges the fastest (shown in Figure 3(a)) indicating that government subsidies have an incentive effect on enterprises' behavior. However, Figure 3(b) shows that the probability convergence corresponding to the government's strategic action becomes slower, by the reason that the subsidy to some extent reduces the government's expected payoffs. The probability convergence of the residents' action shows the least changes (shown in Figure 3(c)), indicating government incentives have less impact on their decision-making. 
TABLE 4: Variable type of the SD model.

\begin{tabular}{|c|c|}
\hline Variable & Type \\
\hline Administrative penalties & Auxiliary \\
\hline Compensation factor & Constant \\
\hline Concentration of pollutants & Constant \\
\hline Cost for enterprise to upgrade facilities & Auxiliary \\
\hline Cost of complaints & Auxiliary \\
\hline Difference in profit while upgrading facilities & Auxiliary \\
\hline Difference in payoffs under governmental regular inspection & Auxiliary \\
\hline Economic penalty & Constant \\
\hline Enterprise's expected payoffs & Auxiliary \\
\hline Enterprise's expected payoffs with upgrading facilities & Auxiliary \\
\hline Enterprise's expected payoffs without upgrading facilities & Auxiliary \\
\hline Illegal emissions & Auxiliary \\
\hline Expected payoffs of governmental regular inspection & Auxiliary \\
\hline Expected payoffs of residents who do not appeal to compensation & Auxiliary \\
\hline Expected payoffs of residents who appeal to compensation & Auxiliary \\
\hline Expected payoffs that the government does irregular inspection & Auxiliary \\
\hline Expected payoffs of government & Auxiliary \\
\hline Government subsidy & Constant \\
\hline Health loss that residents exposed to environment & Auxiliary \\
\hline Local salary & Constant \\
\hline Maintenance cost & Auxiliary \\
\hline Expected payoffs of residents & Auxiliary \\
\hline Power generation & Constant \\
\hline Power generation capacity & Constant \\
\hline Probability change on enterprise & Rate \\
\hline Probability change on government & Rate \\
\hline Probability change on residents & Rate \\
\hline Probability that the government implements regular inspection & Level \\
\hline Probability that residents appeal to compensation & Level \\
\hline Probability that the enterprise upgrades facilities & Level \\
\hline Profit of power generation & Auxiliary \\
\hline Residents' compensation & Auxiliary \\
\hline Standard value of pollutants & Constant \\
\hline The cost of governmental regular inspection & Constant \\
\hline The expected compensation of residents & Auxiliary \\
\hline Cost of waste incineration & Auxiliary \\
\hline Waste treatment capacity & Constant \\
\hline
\end{tabular}

Moreover, the equilibrium strategies for the three players have not been significantly improved, implying that governmental incentives may not be efficient in helping the enterprise motivate technical transformation [56]. Fan and Dong [56] have found that the incentive performance on technological innovation of enterprises is uncertain. In fact, whether an enterprise may undertake technological innovation not only depends upon the capital investment but also links with its ability of research and development as well as the prediction of market competition.

The second scenario is that the local government imposes economic sanctions on the enterprise's illegal behavior, for example, odor emissions without any countermeasures on their prevention, to compel the enterprise to facilitate upgrade of treatment facilities. Figure 4(a) shows that the probability of choosing an upgrade has been significantly increased from 0.66 to 0.82 . Although the final probability for governmental action is 1 , its rate of convergence has been improved, indicating the local government will strengthen the intensity of surveillance, shown in Figure 4(b). Figure 4(c) shows that the probability equilibrium of residents' action keeps nearly the same as 0 . It thus implies that reinforcement of inspection by raising administrative penalties are an effective way to impel the enterprise to improve its environmental quality, by which the residents may satisfy its operation without appealing to ecological compensation. A similar indication has been confirmed by Wei and Lu [57], as they addressed that the regulation in terms of punishment may have a significant impact on the improvement of environmental quality. Jin et al. [58] also revealed that the heavy fine may restrain the enterprise's environmentally unfriendly behavior.

5.3. Discussion. The game theoretical analysis shows that the three players with bounded rationality can obtain equilibrium states without external policy stimulus. For the strategic actions on the local government and residents, they will rapidly transform into a pair of dominant strategies throughout most of the simulation period; that is, the government will implement regular inspection and residents will not complain about the project. No matter whether 


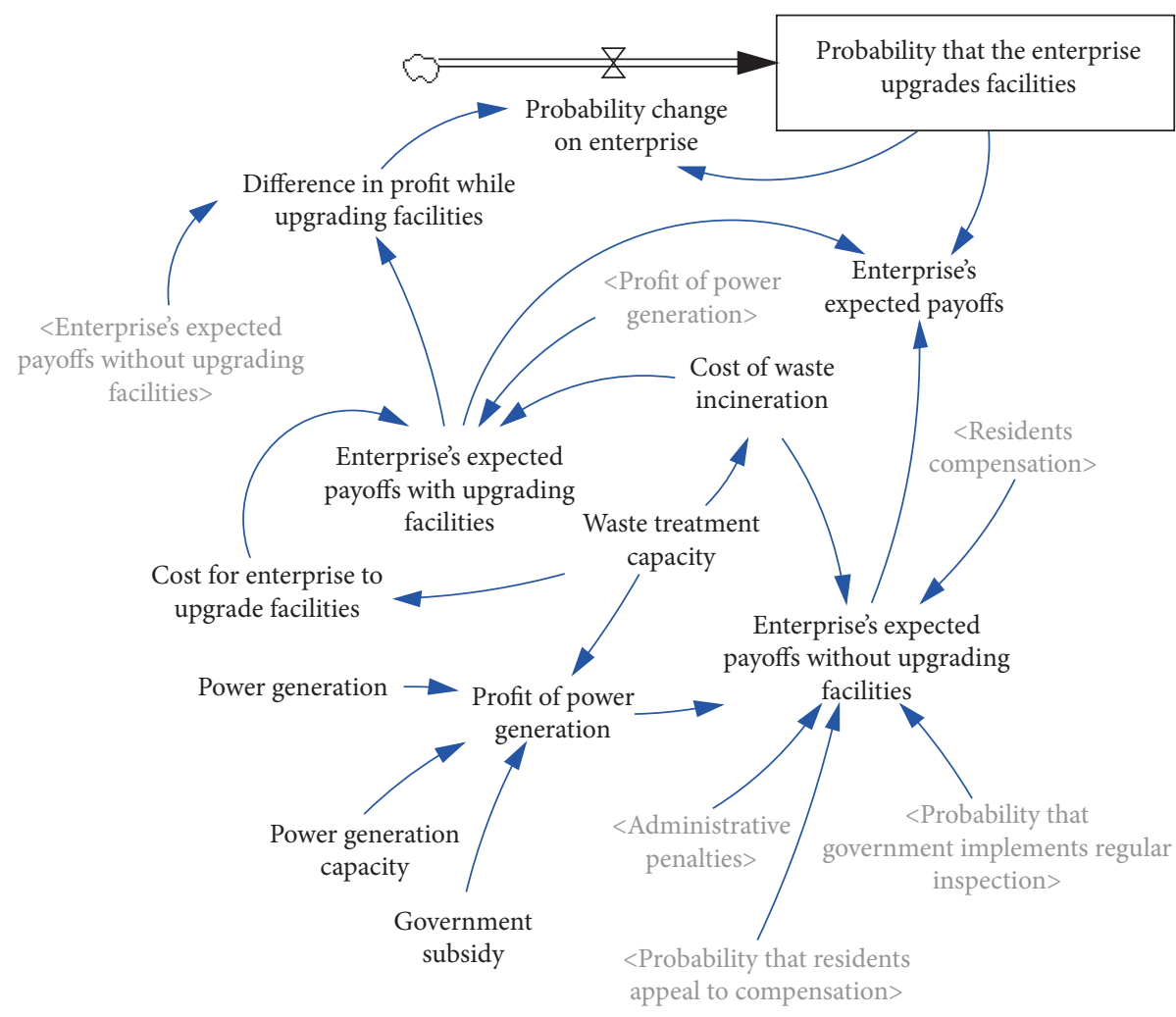

(a)

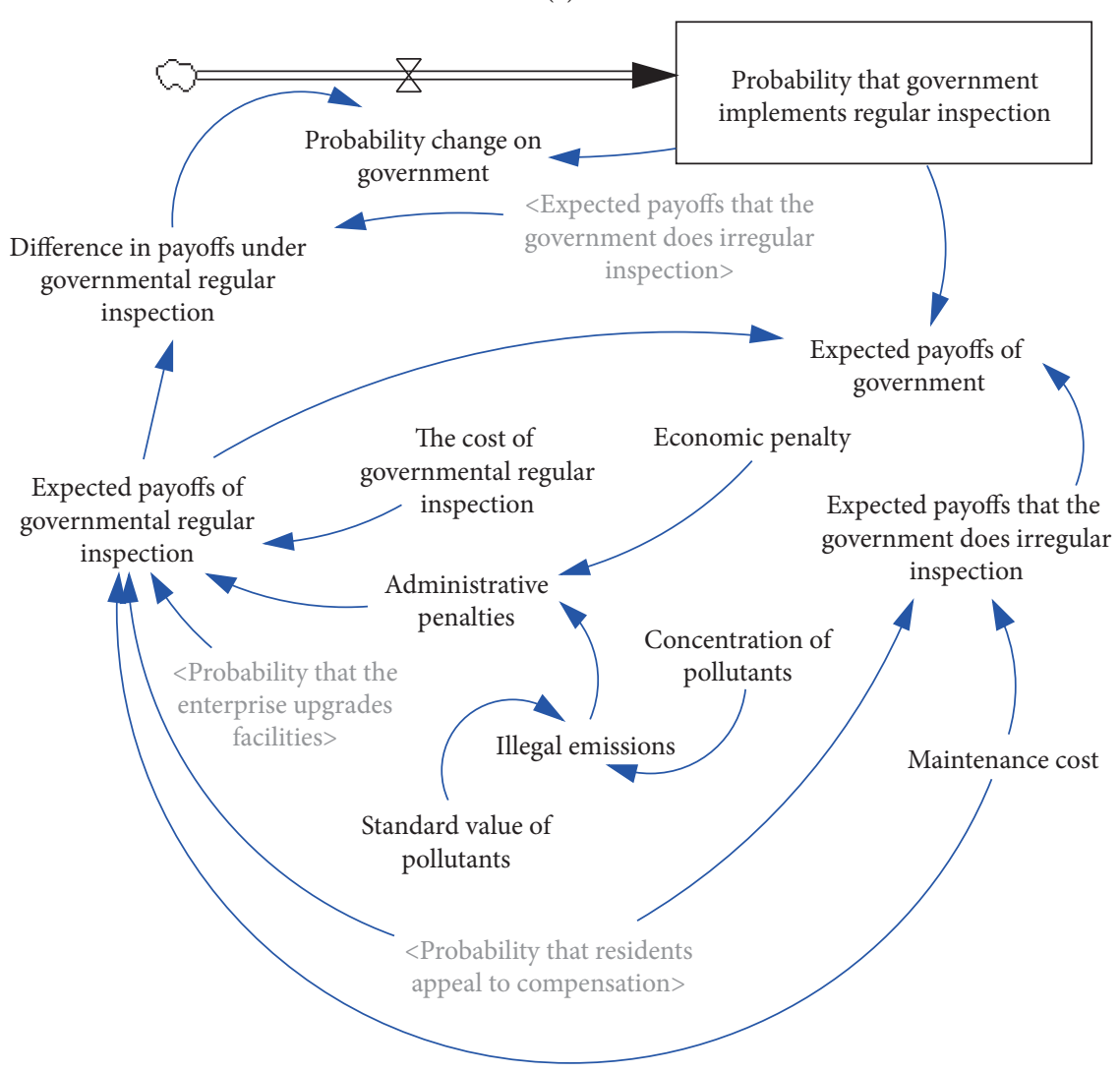

(b)

Figure 1: Continued. 


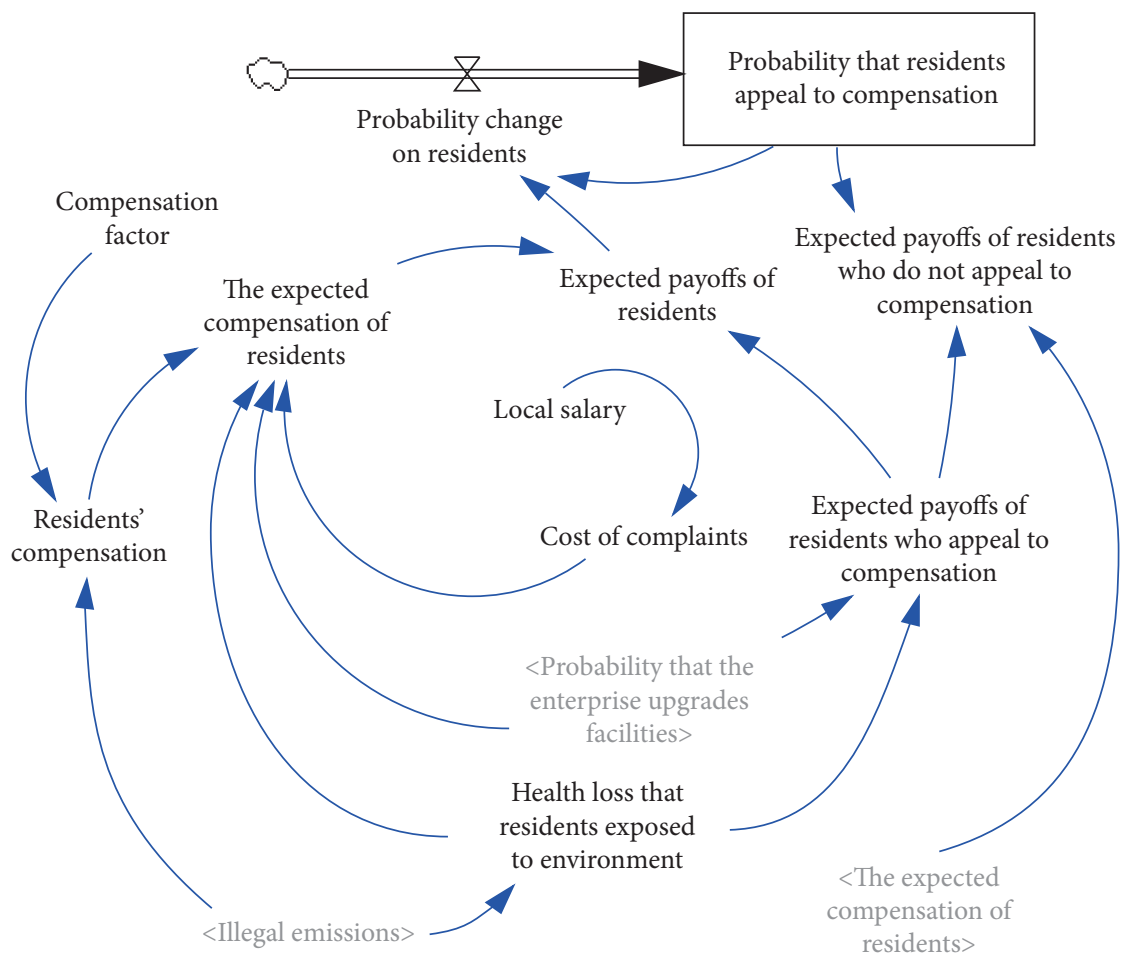

(c)

FIgURE 1: The three players' evolutionary game-based SD model. (a) The enterprise. (b) The government. (c) The residents.

TABLE 5: Interpretation of the key influencing factors.

\begin{tabular}{|c|c|c|}
\hline Parameter & Value & Interpretation \\
\hline $\begin{array}{l}\text { Enterprise's income from power } \\
\text { generation }\left(B_{a}\right)\end{array}$ & - & $\begin{array}{l}\text { The income from power generation can be measured by generating capacity } \\
\text { multiplied by electricity price, in which the electricity price after government subsidy } \\
\text { is } 0.65 \mathrm{CNY} / \mathrm{kwh}[49] .\end{array}$ \\
\hline $\begin{array}{l}\text { Operation and maintenance cost of } \\
\text { incineration plant }\left(A_{e}\right)\end{array}$ & - & $\begin{array}{l}\text { The operation and maintenance cost is derived } \mathrm{f} \\
\text { to } 120 \mathrm{CNY} / \mathrm{t}\end{array}$ \\
\hline $\begin{array}{l}\text { Cost of upgrading treatment facilities } \\
\left(A_{\text {eu }}\right)\end{array}$ & $16 \mathrm{CNY} / \mathrm{t}$ & $\begin{array}{c}\text { The unit cost of waste disposal is increased by } 16 \mathrm{CNY} / \mathrm{t} \text { since the treatment facilities } \\
\text { upgrading [11]. }\end{array}$ \\
\hline Social $\operatorname{cost}\left(A_{g_{1}}\right)$ & - & $\begin{array}{l}\text { It is hypothesized as the expense for government in mec } \\
\text { can be expressed as } T \times A \text {, where } T \text { is consistent with the } \\
\text { on appealing to their compensation and } A \text { is the bas } \\
\text { Ministry of Finance; that is, each one will obtain }\end{array}$ \\
\hline $\begin{array}{l}\text { Cost of residents appealing to } \\
\text { compensation }\left(A_{p}\right)\end{array}$ & - & $\begin{array}{l}\text { Since there are no specific measurements on the cost of complaints, this study } \\
\text { estimates it as } T \times S \text {, where } T \text { is the time that the residents spent for appealing to their } \\
\text { compensation and } S \text { is the local average salary; its value is } 192 \mathrm{CNY} / \text { person/day [52]. }\end{array}$ \\
\hline dents $\left(D_{p}\right)$ & - & $\begin{array}{c}\text { The pollution compensation for residents nearby can be assessed as [53] } \\
K \sum_{i=1}^{n} \max \left(\left(\left(X_{i}(x, y, o)\right) / \overline{x_{t}}\right)-1,0\right) \text {, where } K \text { is the compensation coefficient, } \\
\text { assumed as } 2000[53] ; X_{i}(x, y, 0) \text { is the concentration of the } i \text { th pollutant at the } \\
\text { geographic location }(x, y, 0) \text {; and } \overline{x_{t}} \text { represents the emissions standard of the } i \text { th } \\
\text { pollutant, selected as } 80 \mathrm{mg} / \mathrm{Nm}^{3}[11]\end{array}$ \\
\hline Administrative penalty $\left(D_{g}\right)$ & - & The penalty can be measured as follows [54]: $\left(\left(X_{i}(x, y, o)\right) / \overline{x_{t}}\right) \times 100,000$. \\
\hline $\begin{array}{l}\text { Health loss associated with typical } \\
\text { diseases }(E)\end{array}$ & 424.81 CNY & $\begin{array}{l}\text { different types of diseases caused by pollution, including chronic bronchitis, cor } \\
\text { pulmonale, and lung cancer. } E_{i} \text { is the average cost for the diagnosis and medical } \\
\text { treatment. } P_{i} \text { is the probability of a person suffering from diseases. }\end{array}$ \\
\hline & & \\
\hline ste & $/ \mathrm{t}$ & tigation \\
\hline
\end{tabular}




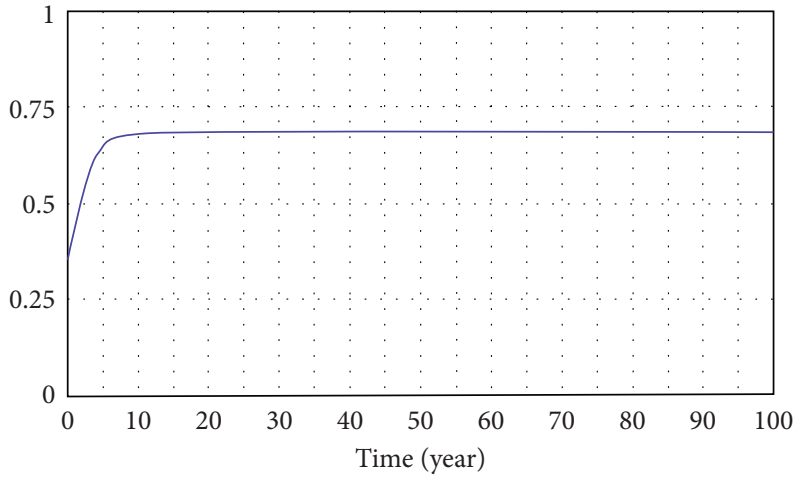

- Initial state

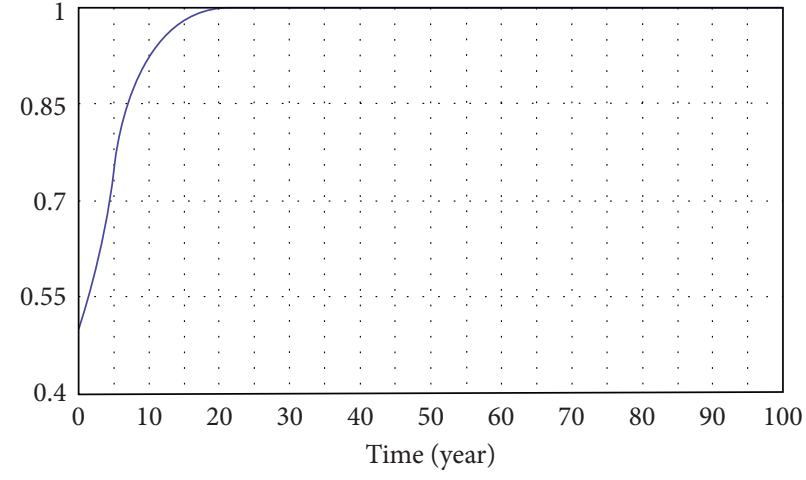

Initial state

(a)

(b)

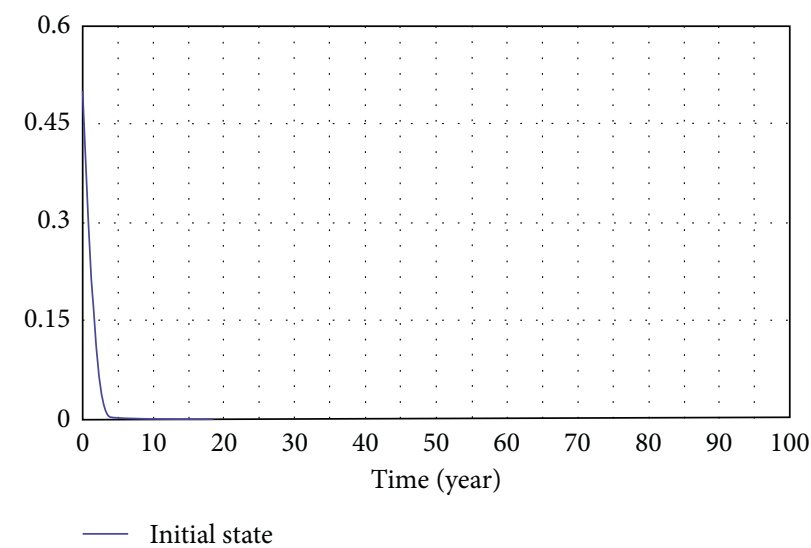

(c)

Figure 2: Simulation results of the proposed game. (a) Probability of the enterprise upgrading facilities. (b) Probability of the government's regular inspection. (c) Probability of the residents appealing to compensation.

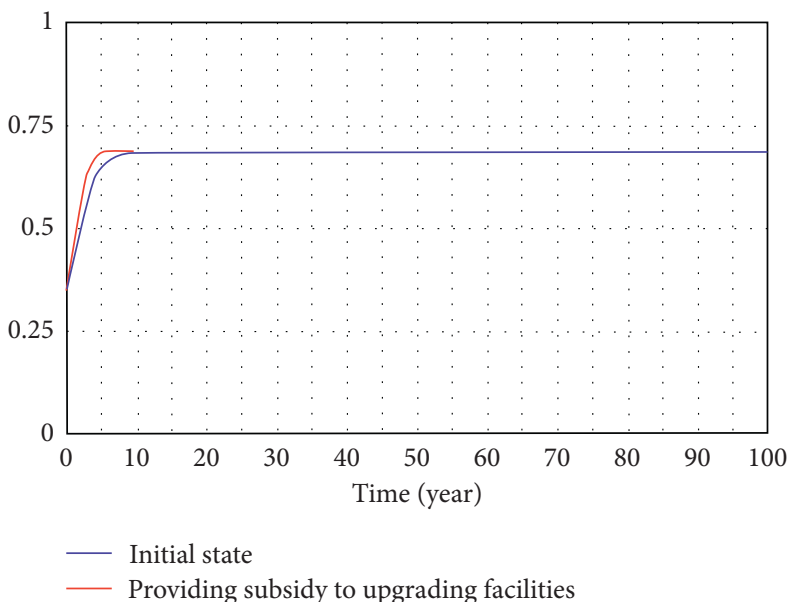

(a)

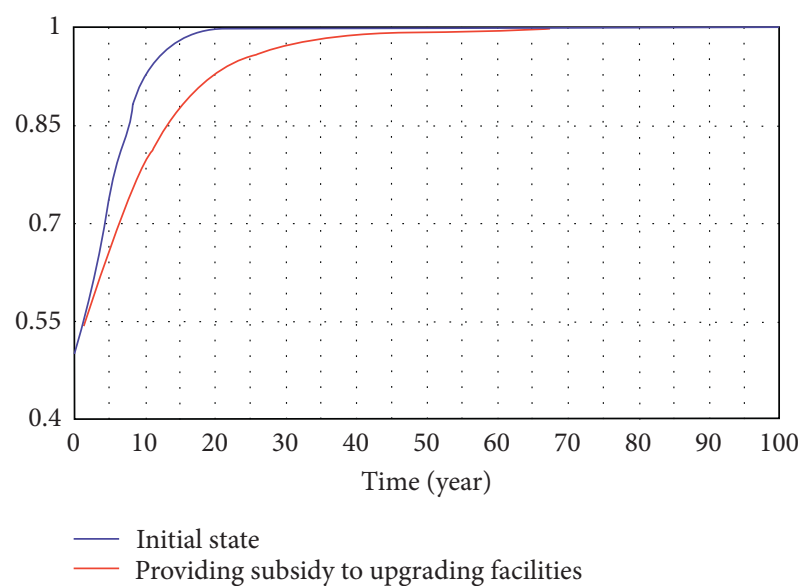

(b)

Figure 3: Continued. 


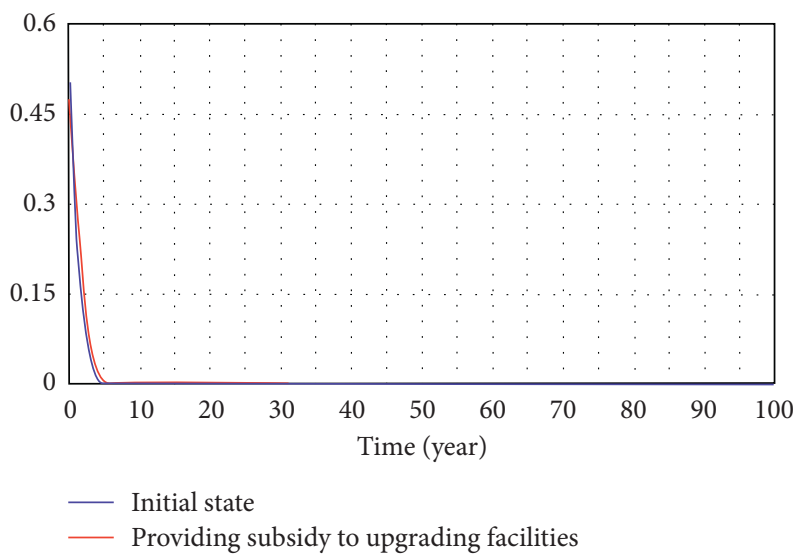

(c)

FIgURe 3: Simulation results by government providing subsidy incentives. (a) Probability of the enterprise upgrading facilities. (b) Probability of the government's regular inspection. (c) Probability of the residents appealing to compensation.

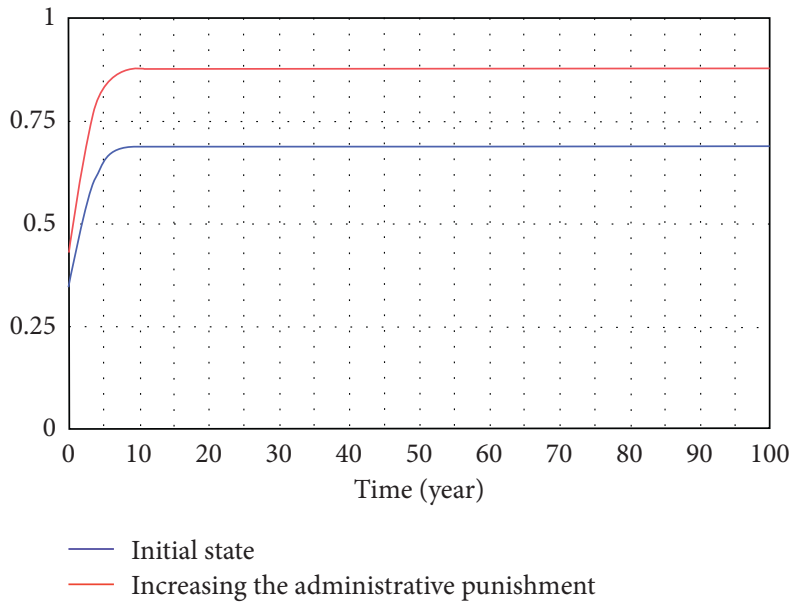

(a)

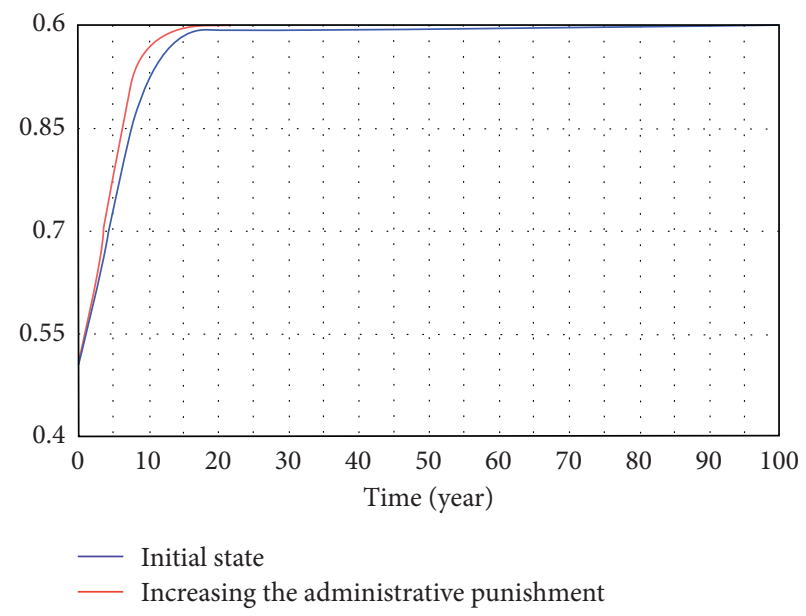

(b)

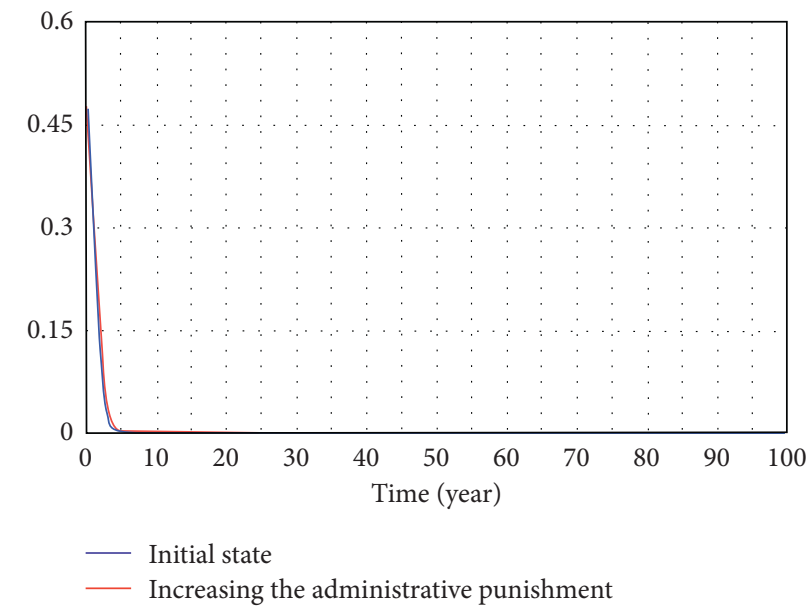

(c)

Figure 4: Simulation results under change of administrative sanction. (a) Probability of the enterprise upgrading facilities. (b) Probability of the government's regular inspection. (c) Probability of the residents appealing to compensation. 


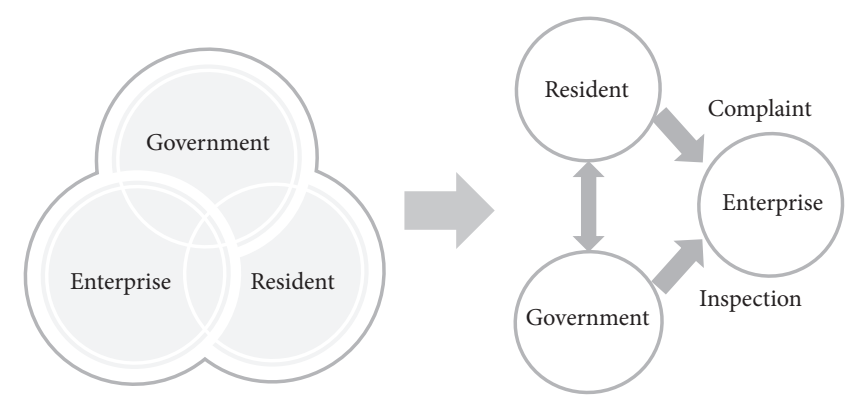

FIgURE 5: The transformation of the relationship among multiplayer with governmental regulation.

imposing policy incentives or administrative sanctions, their strategic actions do not change. Such results may imply that residents' action is not highly related to government policymaking involved in NIMBY conflicts. A possible reason might be that the government maintains regular and strict inspection on the environmental management of the incineration plant to ensure the public interests, by which residents do not tend to call for economic compensation.

The second implication is the strategic option between incentive and punishment. The enterprise's decision-making is closely relevant to governmental regulation. A number of empirical studies have identified that the implementation of incentives is effective in driving research and development for enterprises, thus promoting technological innovation $[21,59]$. However, our simulation result shows no significant change in the enterprise's action when giving governmental subsidies. A possible reason might be that the enterprise itself, as a rational entity, is profit motive oriented, which takes the economic benefits as its bottom line [60]. In such a context, the enterprise gives high priority to maximization of its revenue to maintain its survival, while paying less attention to corporate social responsibility. This is prominent in those industries of waste treatment and disposal in China, for which the governmental subsidy is an important income to cover the cost of operation and maintenance [61, 62]. Unless there is sufficient funding, the enterprises are not willing to provide additional investment voluntarily in improvement of facilities to overcome the NIMBY challenges.

The administrative punishment seems to exert a greater impact on informing the enterprise to take an active response to improve environmental quality. It is apparent that the probability of the enterprise's action on upgrade facilities has been increased by 0.17 , up to 0.83 . To strengthen the punitive measures may enhance the illegal cost to some extent, which has a deterrent impact on the enterprise's environmentally unfriendly behavior [57]. The intensive punishment may accelerate strict surveillance on NIMBY project operation to ensure public interests and reduce the complaints [63]. However, the mechanism of sanction should be carefully designed to avoid trapping into a dilemma regarding trade-offs between economic development and environmental protection [64].

The third implication is that this study provides a path to solve the conflicts, by structuring a linear transformation to simplify the complex relationships among the three stakeholders. In essence, this game takes the enterprise's action as a bridge, not only to respond to governmental policymaking, but also to link with the perceptions of the residents, shown in Figure 5. The governmental intervention is important to drive the enterprise to improve its quality of operations in the environment via regular inspection and strict punishment. The residents may perceive the substantial changes in environmental quality with the enterprise's continuous efforts, thus reducing their risk perceptions and further decreasing possible actions on complaints or even for compensations.

\section{Conclusions}

This study applies evolutionary game theory combined with system dynamics to model the possible strategic actions of stakeholders (government, operational enterprise of the incineration plant, and residents) and predict their variation involved in the NIMBY conflicts with regard to waste incineration. The intervention of policy incentives and administrative punishment is incorporated into the game theoretical analysis, to discriminate their performances on alleviating the conflicts. The results show that there are a pair of dominant strategies for the local government and residents; that is, the government will implement regular inspection on the operations of the incineration plant and the residents will not appeal to compensation. Compared with the governmental incentives and sanctions, the latter policy tool is efficient to help the enterprise motivate technical transformation and improve the environmental quality.

The study contributes to using evolutionary game theory to model possible interactions among three stakeholders, to provide policy implications on mitigating the NIMBY conflicts, for example, the combination of incentives and sanctions. A continuous incentive mechanism may not be effective in responding to the appeals of the operational enterprise and the residents [14]. The enterprise, especially, may highly depend on the incentives for the operations while aggravating financial pressure for the government. Though the economic penalties have a significant driving force to alleviate conflicts, the intensity should be set in an appropriate range. Thus, their combinations may ensure both the economic and environmental performances on the operation of a NIMBY project. 
The study has certain limitations. First, the interactions for the involved stakeholders have been significantly simplified to construct an evolutionary game. Second, the corresponding strategic actions may not fully reflect the actual conflicts among the three players. Future study is expected to improve the game by integration with case studies on waste incineration, to explore optimal solutions of conflicts among government, operational enterprise, and residents.

\section{Data Availability}

The data used to support the findings of this study are available from the corresponding author request.

\section{Conflicts of Interest}

The authors declare that there are no conflicts of interest regarding the publication of this article.

\section{Acknowledgments}

This study was supported by the National Natural Science Foundation of China (no. 41571520), Sichuan Province Cyclic Economy Research Center (nos. XHJJ-2002 and XHJJ-2005), and Sichuan Science and Technology Program (nos. 2019JDJQ0020 and 2020JDTD0003).

\section{References}

[1] K. L. P. Nguyen, Y. H. Chuang, H. W. Chen, and C. C. Chang, "Impacts of socioeconomic changes on municipal solid waste characteristics in Taiwan," Resources, Conservation and Recycling, vol. 161, Article ID 104931, 2020.

[2] Y. Q. Tong, J. F. Liu, and S. Z. Liu, "China is implementing 'Garbage Classification' action," Environmental Pollution, vol. 259, Article ID 113707, 2019.

[3] J. Xu, M. Zhu, and S. Zhao, "Leader-follower optimized approach for carbon-economy equilibrium in the municipal solid waste (MSW) incineration industry," Environmental Science and Pollution Research, vol. 27, no. 26, pp. 3263732658, 2020.

[4] G. Wang, J. Deng, Z. Ma, J. Hao, and J. Jiang, "Characteristics of filterable and condensable particulate matter emitted from two waste incineration power plants in China," Science of the Total Environment, vol. 639, pp. 695-704, 2018.

[5] X. Ren, Y. Che, K. Yang, and Y. Tao, "Risk perception and public acceptance toward a highly protested Waste-to-Energy facility," Waste Management, vol. 48, pp. 528-539, 2016.

[6] L. Sun, E. H. K. Yung, E. H. W. Chan, and D. Zhu, "Issues of NIMBY conflict management from the perspective of stakeholders: a case study in Shanghai," Habitat International, vol. 53, pp. 133-141, 2016.

[7] L. Zhang and D. B. Klenosky, "Residents' perceptions and attitudes toward waste treatment facility sites and their possible conversion: a literature review," Urban Forestry \& Urban Greening, vol. 20, pp. 32-42, 2016.

[8] C. Sun, X. Ouyang, and X. Meng, "Public acceptance towards waste-to-energy power plants: a new quantified assessment based on "willingness to pay"” Journal of Environmental Planning and Management, vol. 62, no. 14, pp. 2459-2477, 2019.
[9] M. Prosperi, M. Lombardi, and A. Spada, "Ex ante assessment of social acceptance of small-scale agro-energy system: a case study in southern Italy," Energy Policy, vol. 124, pp. 346-354, 2019.

[10] State Council of the People's Republic of China, Regulations of the People's Republic of China on the Disclosure of Government Information, 2007, http://www.most.gov.cn/yw/200704/ t20070424_43317.htm.

[11] MEEC (Ministry of Ecology and Environment of the People's Republic of China), Standard for Pollution Control on the Municipal Solid Waste Incineration, 2014, http:// www.mee.gov.cn/ywgz/fgbz/bz/bzwb/gthw/gtfwwrkzbz/ 201405/t20140530_276307.shtml.

[12] MEEC (Ministry of Ecology and Environment of the People's Republic of China), Measures on Public Participation in Environmental Impact Assessment, 2018, http://www.mee.gov.

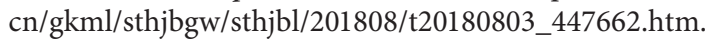

[13] L. Y. Qian, Z. M. Xu, H. F. Pan, and S. P. Pan, "Reachability analysis of new standard for domestic incinerator flue gas," The Administration and Technique of Environmental Monitoring, vol. 28, pp. 57-60, 2016.

[14] L. Ma and L. Zhang, "Evolutionary game analysis of construction waste recycling management in China," Resources, Conservation and Recycling, vol. 161, Article ID 104863, 2020.

[15] R. Zhao, G. Neighbour, M. McGuire, and P. Deutz, "A software based simulation for cleaner production: a game between manufacturers and government," Journal of Loss Prevention in the Process Industries, vol. 26, no. 1, pp. 59-67, 2013.

[16] S. Mikel, S. M. Loreto, I. Amaia et al., "Explaining social acceptance of a municipal waste incineration plant through sociodemographic and psycho-environmental variables," Environmental Pollution, vol. 263, Article ID 114504, 2020.

[17] Y. Liu, Y. J. Ge, B. Xia, C. Y. Cui, X. Y. Jiang, and M. Skitmore, "Enhancing public acceptance towards waste-to-energy incineration projects: lessons learned from a case study in China," Sustainable Cities and Society, vol. 48, Article ID 101582, 2019.

[18] L. J. d. V. B. d. Silva, I. F. S. d. Santos, J. H. R. Mensah, A. T. T. Gonçalves, and R. M. Barros, "Incineration of municipal solid waste in Brazil: an analysis of the economically viable energy potential," Renewable Energy, vol. 149, pp. 1386-1394, 2020.

[19] Y.-t. Bian, L. Xu, J.-S. Li, and X.-q. Liu, "Dynamical evolution of trading behavior on anti-coordination game in complex networks," China Finance Review International, vol. 6, no. 4, pp. 367-379, 2016.

[20] R. Zhao, J. Han, S. Zhong, and Y. Huang, "Interaction between enterprises and consumers in a market of carbon-labeled products: a game theoretical analysis," Environmental Science and Pollution Research, vol. 25, no. 2, pp. 1394-1404, 2018.

[21] R. Zhao, X. Zhou, J. Han, and C. Liu, "For the sustainable performance of the carbon reduction labeling policies under an evolutionary game simulation," Technological Forecasting and Social Change, vol. 112, no. 1, pp. 262-274, 2016.

[22] F. Weller, L.-A. Cecchini, L. Shannon et al., "A system dynamics approach to modelling multiple drivers of the African penguin population on Robben Island, South Africa," Ecological Modelling, vol. 277, pp. 38-56, 2014.

[23] R. Zhao, B. Xi, Y. Liu, J. Su, and S. Liu, "Economic potential of leachate evaporation by using landfill gas: a system dynamics approach," Resources, Conservation and Recycling, vol. 124, pp. 74-84, 2017. 
[24] J. Von Neumann and O. Morgenstern, Theory of Games and Economic Behavior, Princeton University Press, Princeton, NJ, USA, 1944.

[25] M. Abdollahian, Z. Yang, and H. Nelson, "Techno-social energy infrastructure siting: sustainable energy modeling programming (SEMPro)," Journal of Artificial Societies and Social Simulation, vol. 16, no. 3, pp. 1-6, 2013.

[26] A. C. Karmperis, K. Aravossis, I. P. Tatsiopoulos, and A. Sotirchos, "Decision support models for solid waste management: review and game-theoretic approaches," Waste Management, vol. 33, no. 5, pp. 1290-1301, 2013.

[27] A. Soltani, R. Sadiq, and K. Hewage, "Selecting sustainable waste-to-energy technologies for municipal solid waste treatment: a game theory approach for group decisionmaking," Journal of Cleaner Production, vol. 113, pp. 388-399, 2016.

[28] K. Cho and H. Park, "The application of 2 steps fuzzy set qualitative comparative analysis(fs/QCA) to conflict research: focusing on NIMBY facilities conflict," Korean Journal of Policy Analysis and Evaluation, vol. 25, no. 4, pp. 311-333, 2015.

[29] S. W. Mei, W. Wei, and F. Liu, "Game theoretical perspective of power system control and decision making: a brief review of engineering game theory," Control Theory \& Applications, vol. 35, no. 5, pp. 578-587, 2018.

[30] A. B. Da Silva Rocha and G. M. Salomão, "Environmental policy regulation and corporate compliance in evolutionary game models with well-mixed and structured populations," European Journal of Operational Research, vol. 279, no. 2, pp. 486-501, 2019.

[31] R. Xu, Y. Wang, W. Wang, and Y. Ding, "Evolutionary game analysis for third-party governance of environmental pollution," Journal of Ambient Intelligence and Humanized Computing, vol. 10, no. 8, pp. 3143-3154, 2019.

[32] E. Oftadeh, M. Shourian, and B. Saghafian, "An ultimatum game theory based approach for basin scale water allocation conflict resolution," Water Resources Management, vol. 31, no. 13, pp. 4293-4308, 2017.

[33] K. Aghasian, A. Moridi, A. Mirbagheri, and M. Abbaspour, "A conflict resolution method for waste load reallocation in river systems," International Journal of Environmental Science and Technology, vol. 16, no. 1, pp. 79-88, 2019.

[34] J. C. Sheng, W. H. Zhou, and B. Z. Zhu, "The coordination of stakeholder interests in environmental regulation: lessons from China's environmental regulation policies from the perspective of the evolutionary game theory," Journal of Cleaner Production, vol. 249, Article ID 119385, 2020.

[35] G. E. Halkos and G. J. Papageorgiou, "Pollution, environmental taxes and public debt: a game theory setup," Economic Analysis and Policy, vol. 58, pp. 111-120, 2018.

[36] B. Jiang, X. Wang, H. Xue, J. Li, and Y. Gong, "An evolutionary game model analysis on emission control areas in China," Marine Policy, vol. 118, Article ID 104010, 2020.

[37] J. M. Smith, Evolution and the Theory of Games, Cambridge University Press, Cambridge, UK, 1982.

[38] H. Yu, W. Wang, B. H. Yang, and C. F. Li, "Evolutionary game analysis of the stress effect of cross-regional transfer of resource-exhausted enterprises," Complexity, vol. 2019, Article ID 7652430, 2019.

[39] M. You, S. Li, D. Li, Q. Cao, and F. Xu, "Evolutionary game analysis of coal-mine enterprise internal safety inspection system in China based on system dynamics," Resources Policy, vol. 67, Article ID 101673, 2020.
[40] D. Friedman, "Evolutionary games in economics," Econometrica, vol. 59, no. 3, pp. 637-666, 1991.

[41] J. W. Weibull, Evolutionary Game Theory, MIT Press, Cambridge, UK, 1997.

[42] Z. Wang, Q. X. Wang, B. X. Chen, and Y. Wang, "Evolutionary game analysis on behavioral strategies of multiple stakeholders in E-waste recycling industry," Resources, Conservation \& Recycling, vol. 155, Article ID 104618, 2020.

[43] L. X. Liu, Y. C. Zhu, and S. B. Guo, "The evolutionary game analysis of multiple stakeholders in the low-carbon agricultural innovation diffusion," Complexity, vol. 2020, Article ID 6309545, 2020.

[44] J. Song, D. Song, and D. Zhang, "Modeling the concession period and subsidy for BOT waste-to-energy incineration projects," Journal of Construction Engineering and Management, vol. 141, no. 10, Article ID 4015033, 2015.

[45] L. Wang, N. Zhao, and D. H. Liu, "Complex disaster management: a dynamic game among the government, enterprises, and residents," Journal of Cleaner Production, vol. 266, Article ID 122091, 2020.

[46] M. Liu, R. Shadbegian, and B. Zhang, "Does environmental regulation affect labor demand in China? Evidence from the textile printing and dyeing industry," Journal of Environmental Economics and Management, vol. 86, pp. 277-294, 2017.

[47] E. J. Pinker, "An analysis of short-term responses to threats of terrorism,” Management Science, vol. 53, no. 6, pp. 865-880, 2007.

[48] D. H. Liu, "Evolutionary analysis of unexpected incident involving mass participation under different governmental emergency management models," Systems Engineering-Theory \& Practice, vol. 30, no. 11, pp. 1968-1976, 2010.

[49] NDRC (National Development and Reform Commission of the People's Republic of China), Trial Measures for the Management of the Price and Cost-Sharing of Renewable Energy Power Generation, 2006, http://www.gov.cn/ztzl/200620/content_165910.htm.

[50] G. Ding, Study of Business Environment and Strategy of Qinhuangdao Garbage Power Plant, Master thesis, North China Electric Power University, Beijing, China, 2011.

[51] MFC (Ministry of Finance of the People's Republic of China), Administrative Measures on Travel Expenses of Central and State Organs, 2013, http://www.mof.gov.cn/ mofhome/shenzhen/lanmudaohang/zhengcefagui/201408/ t20140812_1125718. html.

[52] SPBS (Sichuan Provincial Bureau of Statistics), An Announcement on the Average Salary of All Employees in Cities and Towns across the Province in 2019, 2020, http://tjj.sc.gov.cn/sctjj/001/ 2020/5/22/eefbba86177a4210985af68d546b3b5d. shtml.

[53] J. Yi, S. Yao, X. Wu, and X. Yao, "Research on the monitoring system of the surrrounding environment and the problem of economic compensation for surrounding residents mear a waste incineration plant," Environmental Engineering, vol. 32, pp. 742-744, 2014.

[54] NPC, The 13th National People's Congress of the People's Republic of China, Law of the People's Republic of China on Prevention and Control of Air Pollution, 2018, http://www. mzyfz.com/html/2015/2019-01-03/content-1379287.html.

[55] Y. Yang, "Economic compensation for waste incineration plants," Finance \& Economy, vol. 24, pp. 157-159, 2014.

[56] R. Fan and L. Dong, "The dynamic analysis and simulation of government subsidy strategies in low-carbon diffusion considering the behavior of heterogeneous agents," Energy Policy, vol. 117, no. 1, pp. 252-262, 2018. 
[57] J. Wei and S. Lu, "Investigation and penalty on major industrial accidents in China: the influence of environmental pressures," Safety Science, vol. 76, pp. 32-41, 2015.

[58] Y. Jin, C. Cheng, and H. Zeng, "Is evil rewarded with evil? the market penalty effect of corporate environmentally irresponsible events," Business Strategy and the Environment, vol. 29 , no. 3, pp. 846-871, 2020.

[59] T. Yigitcanlar, J. Sabatini-Marques, E. M. da-Costa, M. Kamruzzaman, and G. Ioppolo, "Stimulating technological innovation through incentives: perceptions of Australian and Brazilian firms," Technological Forecasting and Social Change, vol. 146, pp. 403-412, 2019.

[60] K. Hjaila, L. Puigjaner, J. M. Laínez, and A. Espuña, "Integrated game-theory modelling for multi enterprise-wide coordination and collaboration under uncertain competitive environment," Computers \& Chemical Engineering, vol. 98, pp. 209-235, 2017.

[61] H. O. Lyamu, M. Anda, and G. Ho, "A review of municipal solid waste management in the BRIC and high-income countries: a thematic framework for low-income countries," Habitat International, vol. 95, p. 2020, Article ID 102097.

[62] L.-T. Yeh, "Analysis of the dynamic electricity revenue inefficiencies of Taiwan's municipal solid waste incineration plants using data envelopment analysis," Waste Management, vol. 107, pp. 28-35, 2020.

[63] L. Zhang, R. Long, Z. Huang, W. Li, and J. Wei, "Evolutionary game analysis on the implementation of subsidy policy for sustainable transportation development," Journal of Cleaner Production, vol. 267, Article ID 122159, 2020.

[64] C. Mira, K. Thaleia, V. D. D. Andy, and S. Jens, "Trade-off between the economic and environmental impact of different decarbonisation strategies for residential buildings," Building and Environment, vol. 155, pp. 137-144, 2019. 